\title{
Covid-19 Pandemic and Mental Disorders
}

\author{
Aliyev NA ${ }^{1 *}$ and Aliyev $\mathrm{ZN}^{2}$ \\ ${ }^{1}$ Department of Psychiatry and Drug Addiction, Azerbaijan State Advanced Training Institute, Baku, Azerbaijan \\ ${ }^{2}$ Department of Psychiatry, Azerbaijan Medical University, Baku, Azerbaijan
}

*Corresponding author: Nadir A. Aliyev, Department of Psychiatry and Drug Addiction, Azerbaijan State Advanced Training Institute, Baku, Azerbaijan.

Received date: July 15, 2020; Accepted date: August 28, 2020; published date: September 14, 2020

Citation: Aliyev NA and Aliyev ZN. COVID-19 pandemic and mental disorders. J Clinical Research and Reports, 5(4); DOI:10.31579/26901919/110

Copyright: (C) 2020 Nadir A. Aliyev. This is an open access article distributed under the Creative Commons Attribution License, which permits unrestricted use, distribution, and reproduction in any medium, provided the original work is properly cited.

\section{Abstract}

Objective: The literature on psychiatric disorders associated with the coronavirus pandemic is scarce. In publications, indicate increased anxiety, depression, and aggression of other mental disorders. However, there are practically isolated cases of mental disorders associated with a pandemic of coronavirus disease.

Materials and Methods: Eligible 50 participants to meeting the DSM-5 criteria for nosophobia, anxiety, and exacerbation of the main diseases of patients with mental.

Results: All examined individuals showed various mental disorders.

Conclusion: despite the fact that the patients examined by us did not suffer from the disease, COVID-19, but they had mental disorders of varying degrees: from neurotic to psychotic disorders.

Keywords: Covid-19 Pandemic; mental disorders

\section{Introduction}

\section{Messages for the general population}

1. The first problem. COVID-19 affects and can affect people from many countries in many geographical areas. When treating people with COVID-19, do not link the disease to any ethnic or nationality. Be merciful to all who are affected, to any country and those who come from it. People affected by COVID-19 have made no mistakes and deserve our support, compassion and mercy. disease caused by the virus itself, which is generally self-limiting, but can be fatal, especially in susceptible, elderly people.

2. The second problem. These are "People who have been treated for COVID-19", "People who have been treated for COVID-19" or "People who have been cured of COVID-19", and their families and loved ones will continue to work after they get rid of COVID-19. To reduce stigma, it is important to distinguish a person from having a personality as defined by COVID-19. Almost everyone who hears about the virus causes anxiety, worry, worry, and suffering.

3. The third problem. Minimize watching, reading or listening to disturbing news about COVID-19; seek information only from reliable sources, and you can basically take practical steps to prepare your plans and protect yourself and your loved ones. Look for information updates once or twice a day. The sudden and continuous spread of news about the accident can cause concern to everyone. Learn the facts; not gossip and misinformation. Regularly gather information from the WHO website and local health authorities' platforms to help you separate the facts from the rumors. Facts can help minimize fears. This problem applies not only to psychiatrists and other psychiatrists who are fully trained for professionals, but also to cadets and students who need to develop their education as well as possible in the current, radically changing environment. They also need our help. [1].

\section{Materials and methods}

\section{All patients was examined}

This was a double-blind, placebo-controlled trial for patients diagnosed with DSM-5 for rapid cycle bipolar disorder. The patients gave their informed, written consent to participate.

The conditions of the conducted researches corresponded to the generally accepted norms of morality, the requirements of ethical and legal norms, as well as the rights, interests and personal dignity of the participants of the studies were observed.

a) Conducted research is adequate to the topic of research work.

b) There is no risk for the subject of research.

c) Participants in the study were informed about the goals, methods, expected benefits of the study and associated with risk and inconvenience in the study.

d) The subject's informed consent about participation in the research was received.

The decision of the Ethical Committee at the Azerbaijan Psychiatric Association on the article of NA. Aliev, Z.N. Aliev "Mental disorders caused by the COVID-19 pandemic" submitted for publication in psychiatric journals: in connection with compliance with its legislative 
requirements and regulatory documents is to approve the article by N.A. Aliyev, Z.N. Aliev "Mental disorders caused by the COVID-19 pandemic". Patients were observed at the Mental Health Center of the Ministry of Health of the Republic of Azerbaijan. The study was conducted from January 01, 2020 to 01 of the June 2020 years.

Also we excluded sexually active subjects with active or unstable epilepsy, other genetic syndromes or congenital infections associated with autistic-like syndromes, prematurity; subjects who have been treated within the previous 30 days by any medication known to have a clearly defined potential for toxicity or with any psychotropic drugs; subjects with clinically significant abnormalities in laboratory tests or physical examination; subjects with a history of hypersensitivity or serious side effects associated with the use any drugs A detailed clinical interview with parents by a clinical expert, accompanied by physical examination and blood analysis, was used to ensure that subjects did not meet any exclusion criteria. A structured clinical interview, for DSM-5 Axis I Disorder, Patient Edition, was used to diagnose anxiety disorders, depressions, nosophobia to DSM-5 [2]. Hundred patients (40 men and 60 women) whom we studied were under observation in Mental Clinic for Outpatients of Baku City of Azerbaijan Republic. The length of the washout was 2 weeks. Patients were washout from the all medications. Eligible participants were required to be between 18 and 65 years of age. We excluded serious medical conditions including with other psychiatric disorders (e.g. bipolar disorder II tipi, schizophrenia, patients judged to be at serious suicidal or homicidal risk, dependence of psychoactive drugs, somatic, neurological illness etc). Also we excluded unstable epilepsy, other genetic syndromes or congenital infections associated with autisticlike syndromes, prematurity; subjects who have been treated within the previous 30 days by any medication known to have a clearly defined potential for toxicity or with any psychotropic drugs; subjects with clinically significant abnormalities in laboratory tests or physical examination; subjects with a history of hypersensitivity or serious side effects associated with the drug use, and subjects who, during the previous 3 months, started new non- pharmacological procedures, such as diet, vitamins and psychosocial therapy. A detailed clinical interview with parents by a clinical expert, accompanied by physical examination and blood analysis, was used to ensure that subjects did not meet any exclusion criteria.

Patients clinically significant of abnormal laboratory or EEG findings were ineligible. Patients before the study had not used antidepressants, antipsychotics, anxiolytics, benzodiazepines, SSRI and venlafaxine. Washout of all medicines was two weeks.

Our Follow-up observation (catamnesus) was conducted from January 01, 2020 to June 01, 2020. The results of follow-up observations showed that patients receiving carbamazepine in combination with lithium are in a state in full remission during for 2.5 years.

Choosing of the antidepressants, anxiolytics, antipsychotics hypnotics and benzodiazepines conducted according to the Textbook of psychopharmacology fifth edition [3].

According to the experience of our Azerbaijan State Advanced Training Institute for Doctors named by A. Aliyev, department of psychiatry and drug addiction, mental disorders caused by the COVID-19 pandemic can be divided into several groups:

1. Nozophobia - Fear get infected of COVID-19 (n=30)

2. Anxiety disorders caused by the COVID-19 epidemic. $(n=30)$

3. Depressions caused by the COVID-19 epidemic. $(n=35)$
4. Exacerbation of the main diseases of patients with mental disorders as a result of the COVID-19 epidemic $(n=3)$

5. Therapy of mental disorders that may occur after quarantine.

6. Other mental disorders caused by the COVID-19 pandemic $(n=2)$

The following treatment methods are recommended for the treatment of mental disorders caused by the COVID-19 pandemic.

I. Pharmacological groups and approximate doses of drugs

\section{Antidepressants}

Amiltriptyline. The starting dose - 20-40 mg / day intramuscular or intravenous. When well tolerated, the daily dose can be increased by 20 $40 \mathrm{mg}$ to $100-150 \mathrm{mg}$. After 7-10 days, when the desired effect is achieved, it is taken orally, in the form of $20 \mathrm{mg}$ injection; the drug is replaced by a per-oral dose of $50 \mathrm{mg}$.

Venlafaxine. Intravenous starting dose - $75 \mathrm{mg}$ once daily. If necessary, the dose is gradually increased over 3-4 days. The daily dose is $150-200$ $\mathrm{mg}$.

Imipiramine. Intravenously, the starting dose is $25-50 \mathrm{mg} /$ day; the average daily dose is $150-250 \mathrm{mg}$ (in the hospital - up to $300 \mathrm{mg} /$ day). The dose can be increased up to. It is taken orally after the effect is achieved.

Clomipramine. Orally, 25-50 mg 3 times a day. Parenteral 25-50 mg / day can be increased to $100-150 \mathrm{mg} /$ day.

Paroxetine. Intravenously, the initial dose is $10 \mathrm{mg} /$ day, in the absence of the desired effect is increased by $10 \mathrm{mg}$ / day to $40 \mathrm{mg} /$ day; maximum dose- $50 \mathrm{mg} /$ day.

Sertraline. Internal, starting dose- $25 \mathrm{mg}$ / day; After 1 week, the dose is increased to $50 \mathrm{mg} /$ day, if necessary, the dose is gradually increased to a maximum over several days ( $50 \mathrm{mg} /$ day) - $200 \mathrm{mg} /$ day.

Trazadon. Internally, 75-150 mg / day, 3 times, up to 300-500 mg / day, maximum - $600 \mathrm{mg} /$ day.

Fluxetine. Internally, the starting dose is $20 \mathrm{mg}$ in the morning; if there is no effect, the dose can be increased for several weeks. Overdose of 20 $\mathrm{mg} /$ day is taken twice (morning and evening). The maximum daily dose is $80 \mathrm{mg}$.

Fluvoxamine. Internally, the average dose is $100-200 \mathrm{mg} /$ day, the maximum is $400 \mathrm{mg} /$ day.

Citaloparor. Intravenous, starting dose $-20 \mathrm{mg} /$ day once, maximum$60 \mathrm{mg} /$ day.

Exitaloprom. Intravenously, the starting dose is a single dose of $10 \mathrm{mg} /$ day, the average daily dose is $20 \mathrm{mg}$.

\section{Anxisolytics}

Alprozalam. Internal, single dose - 0.25-0.5 mg, average daily - 1-2 mg, maximum - 4-6 mg / day.

Buspiron. Internally, the starting dose is $15 \mathrm{mg} /$ day, 3 times, if necessary, the dose can be increased by $5 \mathrm{mg}$ every $2-3$ days. The average daily dose is $20-30 \mathrm{mg}$, the maximum single dose is $30 \mathrm{mg}$, the daily dose is $60 \mathrm{mg}$.

Tofiozepam. Internally, the starting dose is $50 \mathrm{mg}$, the average daily dose is $100 \mathrm{mg}$ (50 $\mathrm{mg}$ in the morning and $50 \mathrm{mg}$ in the afternoon).

Clonozepam. Internally, in small doses - 0.5-2 mg, medium - 4-8 mg, high - 8-16 mg; maximum daily dose- $20 \mathrm{mg}$ 
Bromdihydrochlorphenylbenzodiazepine (Phenazepam). Internal, single dose - 0.5-1.0 mg, average daily dose - 2-3 mg, maximum - 6-8 mg / day.

Chlordiazepoxide. Internal, single dose $-5-10 \mathrm{mg}$, average daily dose30-50 mg 2-3 times.

\section{Neuroleptics}

Alimemazine. Internally, the daily dose is $5-10 \mathrm{mg}$ to $60-80 \mathrm{mg}$ (3-4 times), if necessary, the dose can be increased to $200-400 \mathrm{mg} /$ day. The average daily parenteral dose is $40-50 \mathrm{mg}$ ( $\mathrm{v} / \mathrm{d}$ drops), the starting dose is $25 \mathrm{mg} /$ day and can be gradually increased to $75-100 \mathrm{mg} /$ day.

Holoperidol. Internally, 1.5-3 mg / day, 2-3 times a day, the dose can be gradually increased to $10-15 \mathrm{mg} /$ day, if necessary, $10-15 \mathrm{mg} /$ day; supportive dose- 0.5-5 mg / day. A / d 5-10 mg 2-3 times a day for several days, maximum- $40 \mathrm{mg} / \mathrm{day}$.

Levopromazine. Intravenously, $12.5-50 \mathrm{mg} /$ day to $50-100 \mathrm{mg} / \mathrm{day}$, if necessary $300-400 \mathrm{mg} /$ day parenterally, $25-75 \mathrm{mg} /$ day, then the dose is 100-300 mg / day, 3 times a day , v / d 75-100 mg / day.

Persianazin. Internal, starting dose - $10 \mathrm{mg} /$ day, average daily dose30-40 mg, 2-4 times, maximum-50-100 mg / day.

Sulprid. Internal, oral, intravenous, single dose - 50-100 mg / day, average daily dose - 100-600 mg, maximum dose - $1200 \mathrm{mg} /$ day.

Tioridazine. Internally, the starting dose is $75-200$, the average daily dose is $600 \mathrm{mg} /$ day (several receptions), the maximum daily dose in an inpatient setting is $800 \mathrm{mg}$.

Chlorpromazine. Internally, the starting dose - 25-75 $\mathrm{mg} /$ day, gradually increasing the dose to the average daily - 300-600 mg, 3-4 intravenously.

\section{Normothymics}

Valproate sodium. Internally, starting at $150-300 \mathrm{mg} /$ day, gradually increasing to $600-1200 \mathrm{mg} /$ day.

Lithium carbonate. Orally, the average dose is $300-900 \mathrm{mg} /$ day 3 times a day (prolong foramen $1 \mathrm{~g}$ once a day)

Duration of treatment

The duration of outpatient, including supportive care, ranges from 1 to 2 months. The duration of inpatient treatment is 30-40. Then semi-inpatient and supportive care is provided.

\section{Different types of psychotherapy are applied.}

Psychotherapeutic methods used in depression:

- Cognitive therapy (CT; Beck, 1963, 1964, 1976; Beck, Rusk, Shaw \& Emery, 1979);

- Interpersonal psychotherapy (IPP; Clerman, Weissman, Rounsaville \& Chevron, 1984),

- Cognitive-behavioral analytical systemic psychotherapy (KDSP, McCullough et al., 1996)

- Cognitive analytical psychotherapy (QAP, Ryle, 1997).

\section{Non-drug treatment methods}

- Plants with antidepressant properties

- Ginseng tincture.

- Aralia tincture. (Shrub plant with broom-like flowers and large leaves.
- Novopassit consists of plant components (coconut, pistachio, hops, hawthorn, cucumber (honey mint, lemon)), hibiscus (tropical plant with large red flowers), black peony.

- Persen is made from herbs with antidepressant properties (cucumber, peppermint, chicory).

- Tincture of cinnamon lemon.

Treatment of borderline mental disorders with electrotherapy, hydro- and phototherapy, hyperbaric oxygenation, acupuncture-reflexology, vibromassage, relaxation, massage, gymnastics, deprivation of sleep deprivation.

Electrotherapy: galvanotherapy, electro-sleep, electropuncture

\section{- Hydrotherapy}

- Shower - dusty, rainy, needle, circular, shield shower - intermediate area, Charcoal fountain shower, Scottish shower (hot 38-420 C and cold 13-220 C, question shower massage,

- Baths - local, whirlpool, contrast, oxygen, turpentine

- Russian bath - filled with water vapor, the air temperature should be 40$50{ }^{\circ} \mathrm{C}$.

- Roman bath - dry hot air is supplied either on the floor or in the holes in the wall.

- Turkish bath - the air temperature should be $40-50{ }^{\circ} \mathrm{C}$. Humidity is regulated by heating water in the boiler.

- Finnish bath (sauna) - the air temperature is $70-100{ }^{\circ} \mathrm{C}$, the temperature difference between the floor and the ceiling is $60^{\circ} \mathrm{C}$, the relative humidity is $10-15 \%$.

- Phototherapy - laser, infrared, ultraviolet radiation treatment and prevention. The mechanism of action of phototherapy is based on the reactions of photo physical and photochemical effects by the tissues of the body.

Hyperbaric oxygenation - increases the passive pressure of oxygen in the tissues under an elevated atmosphere.

\section{Rubdown}

Massage is the oldest physical means of affecting the body. Represents a generalized reflex reaction of the organism to some extent in the tissues under the influence of local mechanics. Stimulates the adaptive-trophic functions of the autonomic nervous system due to some biologically active substances (histamine, acetylcholine, etc.) in the humoral environment in the tissues. As a result of the massage, blood and lymph circulation improves. Muscle tone and elasticity, contraction functions increase, resulting in improved muscle function. Massage is applied by hand and apparatus. There are two types of massage: classic and segmental - reflector. Classical therapeutic massage is usually applied every day. The main methods of classical therapeutic massage: rubbing (rubbing), rubbing, rubbing and vibrating. Usually 10-12 courses are conducted, repeated after two months.

\section{Discussion}

We are all responsible for reducing our own risk of infection, and if we become infected, for reducing the risk of infection for others. Each of us can do something to protect vulnerable people in our communities. That is why we continue to talk about solidarity. This is not just a threat to individuals or countries. We are all together, and we can save lives only together [4] 
For psychiatrists, this means solidarity with our patients, solidarity with their families, solidarity with our multidisciplinary colleagues and, most of all, solidarity with each other. We need each other now.

COVID-19 is the most serious public health problem that most of us have ever encountered, and hopefully this will be the worst we will ever face in the future. How psychiatry reacts to this situation will play a large role in determining the nature and role of psychiatry in the coming years. The message from the history of psychiatry is clear: we can accept this challenge.

Royal College of Psychiatrists core values are courage, innovation, respect, collaboration, training and excellence. The COVID-19 pandemic requires that we urgently translate all these values into action. COVID-19 requires no less. Our patients need us now, more than ever [5].

The COVID-19 pandemic is a serious health crisis affecting several countries: to date, more than 720,000 cases and 33,000 confirmed deaths have been reported. Such widespread outbreaks are associated with adverse mental health effects. With this in mind, the existing literature on COVID-19 related to mental health was found by searching the literature in the PubMed database. Published articles have been classified according to their general topics and summarized. Preliminary evidence suggests that symptoms of anxiety and depression (16-28\%) and stress self-esteem $(8 \%)$ are common psychological responses to the COVID-19 pandemic and may be associated with sleep disturbance. A number of individual and structural variables mitigate this risk. When planning services for such population groups, the needs of the relevant people and the necessary preventive instructions should be taken into account. Available literature came from only a few affected countries and may not reflect the experience of people living in other parts of the world. In conclusion, subsyndromic mental health problems are a common reaction to the COVID19 pandemic. More representative studies are needed in other affected countries, especially in vulnerable populations [6].

The coronavirus disease 2019 (COVID-19) pandemic is having a profound effect on all aspects of society, including mental health and physical health. We explore the psychological, social, and neuroscientific effects of COVID-19 and set out the immediate priorities and longer-term strategies for mental health science research. These priorities were informed by surveys of the public and an expert panel convened by the UK Academy of Medical Sciences and the mental health research charity, MQ: Transforming Mental Health, in the first weeks of the pandemic in the UK in March, 2020. We urge UK research funding agencies to work with researchers, people with lived experience, and others to establish a high level coordination group to ensure that these research priorities are addressed, and to allow new ones to be identified over time. The need to maintain high-quality research standards is imperative. International collaboration and a global perspective will be beneficial. An immediate priority is collecting high-quality data on the mental health effects of the COVID-19 pandemic across the whole population and vulnerable groups, and on brain function, cognition, and mental health of patients with COVID-19. There is an urgent need for research to address how mental health consequences for vulnerable groups can be mitigated under pandemic conditions, and on the impact of repeated media consumption and health messaging around COVID-19. Discovery, evaluation, and refinement of mechanistically driven interventions to address the psychological, social, and neuroscientific aspects of the pandemic are required [Emily A Holmes, Rory C O'Connor, V Hugh Perry et al. Multidisciplinary research priorities for the COVID-19 pandemic: a call for action for mental health science [7].
To analyze mental health interventions / actions targeted at healthcare providers who assist patients with suspected or diagnosed COVID-19. The COVID-19 pandemic forces healthcare providers to manage their mental health and the mental health of patients. It is important to know and reflect on country initiatives to support the mental health of healthcare providers during a pandemic, and to help rethink the planning, implementation, and evaluation of strategies to be used in Brazil. Mental health activities that supported the care of health workers who are at the forefront of care, especially those based on identifying the disease, proper use of personal protective equipment, and mapping of these emotionally weakened specialists, could be listed. and / or mental distress before the pandemic, in addition to the emotional support offered through digital platforms [8].

History and Discovery, structure-activity relationships, pharmacological profiles, mechanisms of action, pharmacokinetics and disposition, indications and efficacy response, side effects and toxicology, drug-drug interactions antidepressants, anxiolytics, antipsychotics hypnotics and benzodiazepines are described in detail in the literature [3]. Therefore, we will not dwell on them.

\section{Conclusion}

Psychopharmacological Treatment of Depression, Anxiety and Related Disorders, Insomnia in Mental disorders caused by the COVID-19 pandemic is necessary. Treatment should be 1-2 months, with low doses of the above drugs. Our Follow-up observation (catamnesus) was showed that patients receiving are in a state in full remission. Treatment tactics of mental disorders caused by the COVID-19 pandemic should target the underlying psychopathological syndrome.

\section{Acknowledgment}

The authors would like to thank staff of the Mental Health Center of the Ministry of Health of the Republic of Azerbaijan

\section{References}

1. Advice and guidance from WHO on COVID-19

2. American Psychiatric Association.Diagnostic and Statistical Manual of Mental Disorders, Fifth Edition (DSM-5). American Psychiatric Association. 2013.

3. The American Psychiatric Association Publishing. Textbook of psychopharmacology fifth edition. Edited by Alan F. Schatzberg, M.D. Charles B. Nemeroff, M.D., Ph.D. 2017 American Psychiatric Association Publishing. 2879 pp.

4. World Health Organization (WHO). WHO DirectorGeneral's Opening Remarks at the Media Briefing on COVID-19 - 5 March 2020. WHO, 2020.

5. Brendan D. Kelly. Coronavirus disease: challenges for psychiatry. The British Journal of Psychiatry (2020) 217, 352-353.

6. Ravi Philip Rajkumar. COVID-19 and Mental Health: A Review of the Existing Literature. Asian J Psychiatr. 2020 Apr 10;52:102066. PMID: 32302935.

7. Emily A Holmes, Rory C O'Connor, V Hugh Perry et al. MultidisciplinaryresearchprioritiesfortheCOVID-19 pandemic: acallforactionformentalhealthscience. Lancet Psychiatry 2020. Published Online. April 15, 2020.

8. Dandara A. Reis da Silva, Rodrigo F. Weyll Pimentel Magno. das Merces. Covid-19 and the pandemic of fear: reflections on mental health. Revista de Saúde Pública. Pint version ISSN 0034-8910On-line version ISSN 1518-8787. Rev. Saúde Pública vol.54 São Paulo 2020 Epub May 20, 2020. 